\section{(coserenth Acute Medicine}

\title{
Management of Copperhead Snake Envenomation
}

\author{
Kevin Baumgartner Michael Mullins \\ Medical Toxicology, Emergency Medicine, Washington University School of Medicine, \\ St. Louis, MO, USA
}

Dear Editor,

We read with interest the case report of copperhead snake envenomation in pregnancy published by Wang et al. [1]. We appreciate their valuable addition to the scarce literature regarding the management of snake envenomation in pregnancy. We believe that several points raised in their article would benefit from clarification.

The authors state that "hypersensitivity reactions and serum sickness develop in 8 and $13 \%$ of patients treated with CroFab, respectively." Although a specific citation is not provided, these figures are likely taken from a 2012 meta-analysis by Schaeffer et al. [2]. Since the publication of this study, additional research has been published which suggests that the rate of immune adverse reactions to Crotalidae polyvalent immune Fab antivenom (FabAV) is likely even lower, and that reactions are generally mild when they do occur. Mullins et al. [3] found no cases of serum sickness and no cases of severe immediate hypersensitivity reaction in their randomized trial of FabAV versus placebo for copperhead envenomation. A recent review of the North American Snakebite Registry by Kleinschmidt et al. [4] found that acute adverse events occurred in $2.7 \%$ of patients receiving FabAV and that the rate of severe reactions (such as bronchospasm, hypotension, or angioedema) was only 1.1\%. Khobrani et al. [5] reviewed state poison center data and found an adverse event rate of 1.4\%; one patient was treated with an epinephrine infusion, and no other patients required vasoactive medications or respiratory interventions.

Taken together, these data suggest that observation "for at least $24 \mathrm{~h}$ after administration of the last dose," as recommended by the authors, is likely unnecessary. In our clinical practice, we frequently discharge patients with copperhead envenomation within $6 \mathrm{~h}$ of the last FabAV dose. Although the authors did not directly address the clinical setting of treatment and observation, we would also like to note that, while it is reasonable to administer a patient's first dose of FabAV in an acute or critical care setting such as an emergency department or 
intensive care unit, a patient who tolerates her initial dose may safely receive any additional indicated doses in a general hospital ward or other less monitored setting [6].

We would also like to address the authors' discussion of laboratory evaluation for coagulopathy. While serious and life-threatening coagulopathy can be seen in patients suffering from rattlesnake envenomation, it is our experience that copperhead envenomation does not cause significant coagulopathy. A large retrospective review of patients with copperhead envenomation presenting to 2 hospitals in Missouri [7] found no bleeding complications and generally normal or near-normal laboratory parameters of coagulation. These results were confirmed by another retrospective review of patients with copperhead envenomation presenting to 3 hospitals in Virginia [8]. We may check laboratory parameters of coagulation on presentation, especially if the identification of the envenomating snake is uncertain, but generally do not repeat or trend these tests. Repeated "laboratory evaluation after receiving the last dose [of FabAV]" as discussed by the authors is likely unnecessary in patients with copperhead envenomation, who are not at risk for "delayed onset of recurrent coagulopathy."

\section{Statement of Ethics}

Ethics approval was not required for this letter to the editor.

\section{Disclosure Statement}

The authors have no conflicts of interest to disclose.

\section{Funding Sources}

No funding was received.

\section{Author Contributions}

Drs. Baumgartner and Mullins prepared the letter.

\section{References}

1 Wang MJ, Lu MY, Ausbeck EB, Harper LM. Obstetric management of copperhead snake envenomation in pregnancy: a case report. Case Rep Acute Med. 2019;2(2):35-41.

2 Schaeffer TH, Khatri V, Reifler LM, Lavonas EJ. Incidence of immediate hypersensitivity reaction and serum sickness following administration of Crotalidae polyvalent immune Fab antivenom: a meta-analysis. Acad Emerg Med. 2012 Feb;19(2):121-31.

3 Mullins ME, Gerardo CJ, Bush SP, Rose SR, Greene S, Quackenbush EB, et al. Adverse events in the efficacy of Crotalidae polyvalent immune Fab antivenom vs placebo in recovery from copperhead snakebite trial. South Med J. 2018 Dec;111(12):716-20.

4 Kleinschmidt K, Ruha AM, Campleman S, Brent J, Wax P; ToxIC North American Snakebite Registry Group. Acute adverse events associated with the administration of Crotalidae polyvalent immune Fab antivenom within the North American Snakebite Registry. Clin Toxicol (Phila). 2018 Nov;56(11):1115-20.

5 Khobrani M, Huckleberry Y, Boesen KJ, Aljabri A, Alharthi M, Patanwala AE. Incidence of allergic reactions to Crotalidae polyvalent immune Fab. Clin Toxicol (Phila). 2019 Mar;57(3):164-7. 
6 Lavonas EJ, Ruha AM, Banner W, Bebarta V, Bernstein JN, Bush SP, et al.; Rocky Mountain Poison and Drug Center, Denver Health and Hospital Authority. Unified treatment algorithm for the management of crotaline snakebite in the United States: results of an evidence-informed consensus workshop. BMC Emerg Med. 2011 Feb;11(1):2.

7 Ali AJ, Horwitz DA, Mullins ME. Lack of coagulopathy after copperhead snakebites. Ann Emerg Med. 2015 Apr;65(4):404-9.

8 Wills BK, Billet M, Rose SR, Cumpston KL, Counselman F, Shaw KJ, et al. Prevalence of hematologic toxicity from copperhead envenomation: an observational study. Clin Toxicol (Phila). 2019 Jul;25:1-4. 